\title{
Nitretação por descargas elétricas da liga Ti-6Al-4V com adição de pó abrasivo SiC ao fluido dielétrico
}

\author{
Nitriding of the Ti-6Al-4V alloy using electrical \\ discharge machining with addition of $\mathrm{SiC}$ \\ abrasive powder in the dielectric fluid
}

\author{
Roberta Nunes Nery dos Santos ${ }^{1}$, Ernane Rodrigues da Silva ${ }^{1}$, \\ Victor Souza Esteves Lima ${ }^{1}$, Aderci Freitas Filho ${ }^{1}$
}

\footnotetext{
${ }^{1}$ Departamento de Engenharia de Materiais - CEFET-MG, CP: 30421 - 169, Belo Horizonte, Minas Gerais, Brasil. e-mail: robertannery@gmail.com, ernane@cefetmg.br, victorselima@gmail.com, aderciff@gmail.com
}

\begin{abstract}
RESUMO
O processo de nitretação que usa Usinagem por Descargas Elétricas é um método que associa a capacidade de usinar superfícies complexas com a obtenção de tratamento termoquímico de nitretação. A fonte de nitrogênio é proveniente da uréia, que compõe o fluido dielétrico juntamente com água deionizada. A liga de titânio Ti-6Al$4 \mathrm{~V}$ possui larga aplicabilidade no mercado, principalmente, por apresentar excelentes propriedades mecânicas como alta resistência à tração e à corrosão, como também baixa densidade. Contudo, a liga não possui boa resistência ao desgaste por deslizamento, o que impede aplicá-la como matéria prima de peças sujeitas à estas condições. Dessa forma, a nitretação por descargas elétricas pode melhorar significativamente a resistência ao desgaste por deslizamento da liga de titânio. O equipamento utilizado nessa pesquisa foi uma máquina de eletroerosão por penetração. Adequações na máquina foram necessárias para que o fluído dielétrico utilizado não contaminasse o óleo mineral, fluído original do equipamento. Utilizou-se grafita como eletrodo ferramenta. Pó abrasivo de carbeto de silício $\mathrm{SiC}$ de granulometria de 600 mesh foi adicionado à solução aquosa, utilizada como fluído dielétrico, contendo uréia diluída em água deionizada. As amostras foram caracterizadas pelas técnicas de microscopia óptica, DRX, MEV, ensaio de microdureza Vickers e medição da rugosidade superficial. Os resultados obtidos mostraram formação de camadas superficiais enriquecidas por plasma eletrolítico com nitrogênio, formando o composto cerâmico TiN de elevada dureza. Essa camada possui espessura média $104 \mu \mathrm{m}$ e sua formação encontra-se presente em toda a superfície da amostra. Foi constatado aumento da dureza superficial em relação ao material base em torno de $52 \%$ e uma redução da rugosidade em torno de $31 \%$, quando comparado ao processo de nitretação por descargas elétricas, sem adição do pó abrasivo.
\end{abstract}

Palavras-chave: Usinagem por Descargas Elétricas, pó abrasivo, liga de titânio, camada nitretada.

\section{ABSTRACT}

The nitriding process using Electric Discharge Machining is a method that associates the ability to process complex surfaces with the obtaining of thermochemical treatment of nitriding. The titanium alloy Ti-6Al-4V has a wide applicability in the market, mainly because it presents excellent mechanical properties like high tensile strength, corrosion as well as low density. However, the alloy does not have good resistance to sliding wear, which prevents it from being applied as a raw material for parts subject to these conditions. Therefore, electrical discharge nitriding can significantly improve the slip wear resistance of the titanium alloy. The equipment used in this research was a conventional sink EDM machine. Adequations in the machine were necessary so that the dielectric fluid used did not contaminate the mineral oil, original equipment fluid. The graphite electrode was used as a tool electrode. SiC silicon carbide abrasive powder of 600 mesh granulometry was added to the aqueous solution formed by deionized water and urea, used as dielectric fluid. The samples were characterized by optical microscopy, X-ray diffraction (XRD), SEM, Vickers microhardness test and surface roughness measurements. The results obtained showed the formation of superficial layers enriched by electrolytic plasma with nitrogen, forming the ceramic compound TiN of high hardness. This layer has an average thickness of $104 \mu \mathrm{m}$ and its formation is present on every surface of the sample. It was observed an increase of the surface hardness in relation to the base material around $52 \%$ and a reduction of the roughness around $31 \%$ when compared to the 
nitriding process by electric discharges, without addition of the abrasive powder.

Keywords: Electrical discharge machining, abrasive powder, titanium alloy, nitrided layer.

\section{INTRODUÇÃO}

A usinagem por descargas elétricas - Electrical Discharge Machining EDM - tornou-se um processo indispensável para a produção industrial moderna, principalmente, pela capacidade de produzir peças de geometrias complexas e de alto grau de precisão em materiais de difícil usinabilidade, tais como ligas resistentes ao calor, as superligas e carbonetos. A integração da máquina de EDM aos processos computacionais integrados reduziu ainda mais os tempos de manutenção e de operação [1]. Os méritos da EDM permitem a usinagem de qualquer material condutor elétrico, geometria e dureza diversas, pois associa bom desempenho e custo $\mathrm{x}$ benefício, como também têm atraído diversas pesquisas para garantir ganhos mais significativos a esse método.

Apesar de EDM ser um processo bem consolidado e amplamente empregado, pesquisas constantes são aplicadas com o intuito de obter melhorias e integração de métodos industriais. Estudos com ligas de titânio mostraram que é possível enriquecer a superfície do material com nitretos, a partir da usinagem por EDM, utilizando como fluido dielétrico água destilada e uréia, sendo esta a fonte do nitrogênio [2] [3]. SANTOS [4] e SILVA [5] realizaram estudos com o aço ABNT 4140 e obtiveram nitretação por meio de uma máquina de EDM com camadas nitretadas e zona refundida de $25 \mu \mathrm{m}$ e $45 \mu \mathrm{m}$ respectivamente utilizando como fluido dielétrico água deionizada e uréia em concentrações distintas. Tais pesquisas viabilizaram o desenvolvimento de um novo processo de usinagem que possibilita associar técnicas outrora realizadas separadamente, denominado Nitretação por Descargas Elétricas - NDE.

O custo da EDM pode ser impactado pelo maior tempo de usinagem se comparado a outros processos de usinagem disponíveis. Com o intuito de melhorar a eficiência do processo, é possível adicionar pó abrasivo ao fluido dielétrico [6]. Essa adição foi estudada de forma pioneira, a partir da década de 1980, e mostrou um aumento de $60 \%$ na taxa de remoção do material em aço de baixo teor de carbono, utilizando eletrodo de cobre [7]. Desde então, pesquisadores comprovaram melhor desempenho dos processos, como por exemplo: melhoria do acabamento superficial; aumento da taxa de remoção do material (TRM); redução da taxa de desgaste do eletrodo (TD) [8]. Essas melhorias são atribuídas à redução da energia da descarga e à distribuição uniforme do pó na área da usinagem [6]. A adição do pó abrasivo diminui a resistividade dielétrica, o que gera descargas elétricas precoces, tornando a fenda de trabalho maior e dispersando uniformemente os pontos de descarga, melhorando assim, o desempenho da usinagem e o acabamento superficial [9]. No entanto, estes efeitos não são possíveis em todos os pós-abrasivos, uma vez que sua densidade, resistividade elétrica, condutividade térmica, juntamente com a concentração e tamanho das partículas, são altamente determinantes para a melhoria do desempenho do processo [10].

RIZI et al. [11] estudaram o efeito da adição de carbeto de silício (SiC) ao fluido dielétrico na usinagem por EDM em uma liga de titânio Ti-6Al-4V. Verificou-se, por meio de microscopia eletrônica de varredura (MEV), que, após adicionar o pó à solução dielétrica, a rugosidade da superfície foi significativamente reduzida. Os pesquisadores atribuíram tal melhoria à redução da resistência elétrica, que tornará a solução mais condutora, aumentando assim a distância entre o eletrodo e a peça e consequentemente, o canal de plasma. O efeito é uma redução da intensidade do dano criado pelo arco elétrico, que provoca remoções na superfície do material mais largas e de menor profundidade, melhorando assim o aspecto superficial. CHOW et al. [12] adicionaram pó de carbeto de silício a água pura e utilizaram como fluido dielétrico para micro EDM da liga de titânio Ti-6Al-4V. Os experimentos compararam desempenho, acabamento superficial, impacto da polaridade e concentração do pó quando usinado com e sem o carbeto de silício. Os resultados mostraram que a adição de pó abrasivo a água pura produziu maior taxa de remoção de material e desgaste do eletrodo relativamente baixo. Quando se utilizou água pura com carbeto de silício em pó, o gap (fenda de trabalho) foi maior devido à alta condutividade gerada no fluido que, por essa razão, podem dispersar a energia de descarga que refina a aspereza da superfície (redução da rugosidade) de forma eficaz.

As pesquisas adicionando pó abrasivo ao processo de EDM apresentaram resultados satisfatórios, contudo nenhum experimento havia sido realizado com pós-abrasivos no processo de NDE. Portanto, de forma pioneira, tem-se como objetivo investigar a influência do pó abrasivo de carbeto de silício na nitretação por descargas elétricas para avaliar a espessura da camada nitretada formada, sua uniformidade, dureza e a rugosidade superficial da amostra após nitretação. 


\section{MATERIAIS E MÉTODOS}

O material utilizado para realização dos corpos de prova foi a liga de titânio Ti-6Al-4V. As amostras foram preparadas com dimensões de $19 \mathrm{~mm}$ de diâmetro e $12 \mathrm{~mm}$ de comprimento em um torno convencional. Sendo que seis amostras foram usinadas. Como eletrodo ferramenta, utilizou-se a grafita em barra, com dimensões de 22 $\mathrm{mm}$ de diâmetro e $25 \mathrm{~mm}$ de comprimento.

\subsection{Fluido dielétrico}

Como fluído dielétrico foi utilizada água deionizada e uréia. A condutividade foi aferida com um condutivímetro portátil, que opera com incertezas de $\pm 2 \%$, com leituras na faixa de 0 a $1999 \mu \mathrm{S} / \mathrm{cm}$. Foram preparados 30 litros de solução aquosa de água deionizada e uréia em concentração de 33 g/l. Após a primeira etapa de realização dos testes, quando três amostras foram usinadas com água e uréia como fluido dielétrico, foram adicionados $500 \mathrm{~g}$ em pó de carbeto de silício com granulometria de 600 mesh, produzindo uma concentração de 16,7 g/l, para então, realizar a usinagem das três amostras restantes.

\subsection{Máquina para usinagem por descargas elétricas}

O processo de usinagem foi realizado em uma máquina de EDM por penetração adaptada, modelo Eletroplus - 540/SERVSPARK conforme ilustrado na figura 1a.
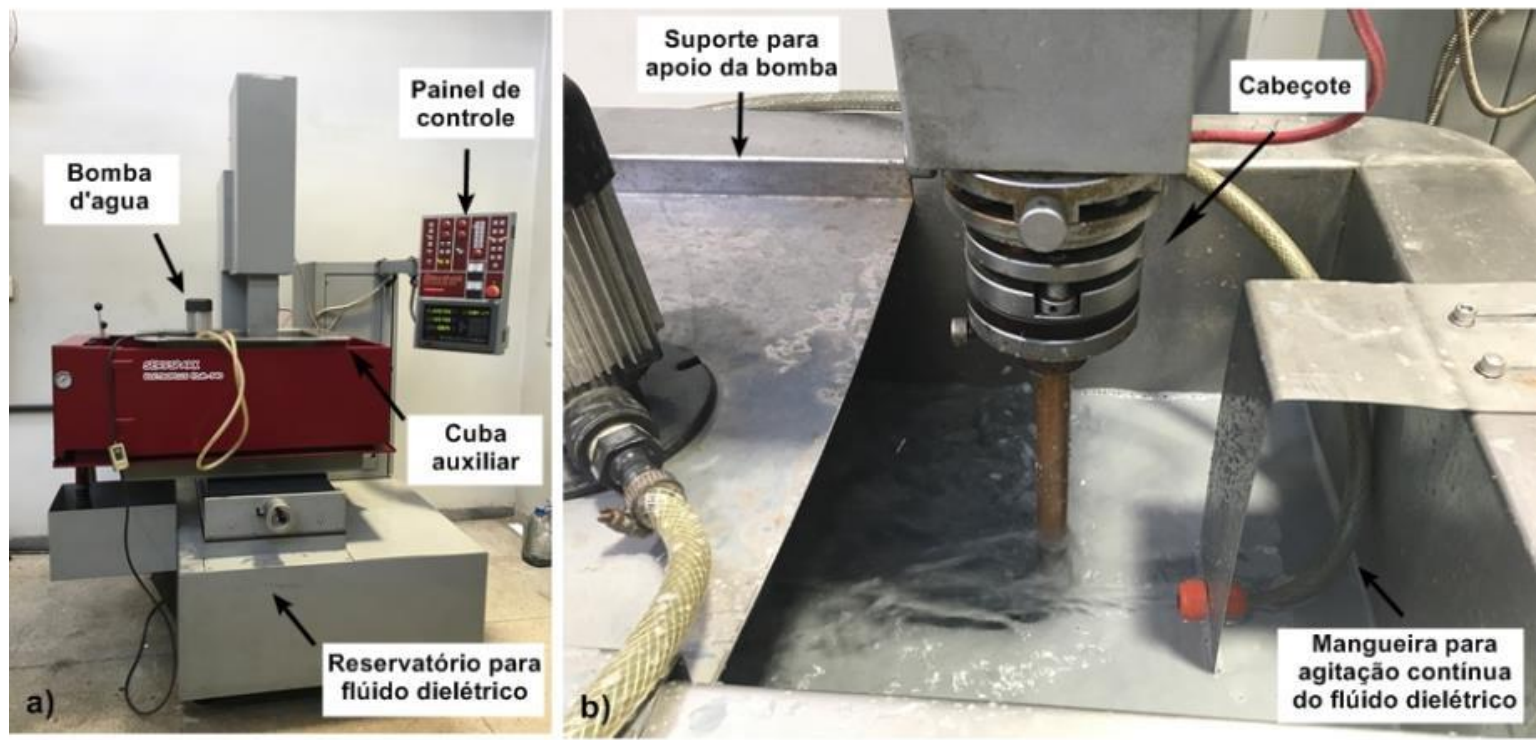

Figura 1: a) Máquina de eletroerosão utilizada no processo NDE b) Detalhes das adaptações realizadas no equipamento.

A adaptação consiste em uma cuba removível com capacidade de 105 litros para comportar a solução de água deionizada e uréia, fabricada de aço inoxidável AISI 304, impedindo que a solução contamine os componentes originais do equipamento. Outra adaptação é a utilização de uma bomba modelo CD 30002 com vazão de 51 litros por minuto e pressão de 2 metros de coluna d'agua, que tem por objetivo realizar a lavagem da fenda de trabalho entre o eletrodo ferramenta e a peça, conforme ilustrado na figura $1 \mathrm{~b}$, e garantir que o fluido e o pó abrasivo recirculem durante todo o processo evitando que o pó decante no fundo da cuba, garantindo assim que o fluido se mantenha sempre em agitação.

Internamente a cuba, há um sistema de fixação da amostra, também denominado porta amostra, e um suporte para fixação do eletrodo ferramenta durante a usinagem. A figura 2 ilustra o sistema de fixação dos eletrodos, que, por parafusos, fixa tanto a peça no porta amostra, quanto o eletrodo ferramenta em seu suporte, a fim de possibilitar a intercambiabilidade. 


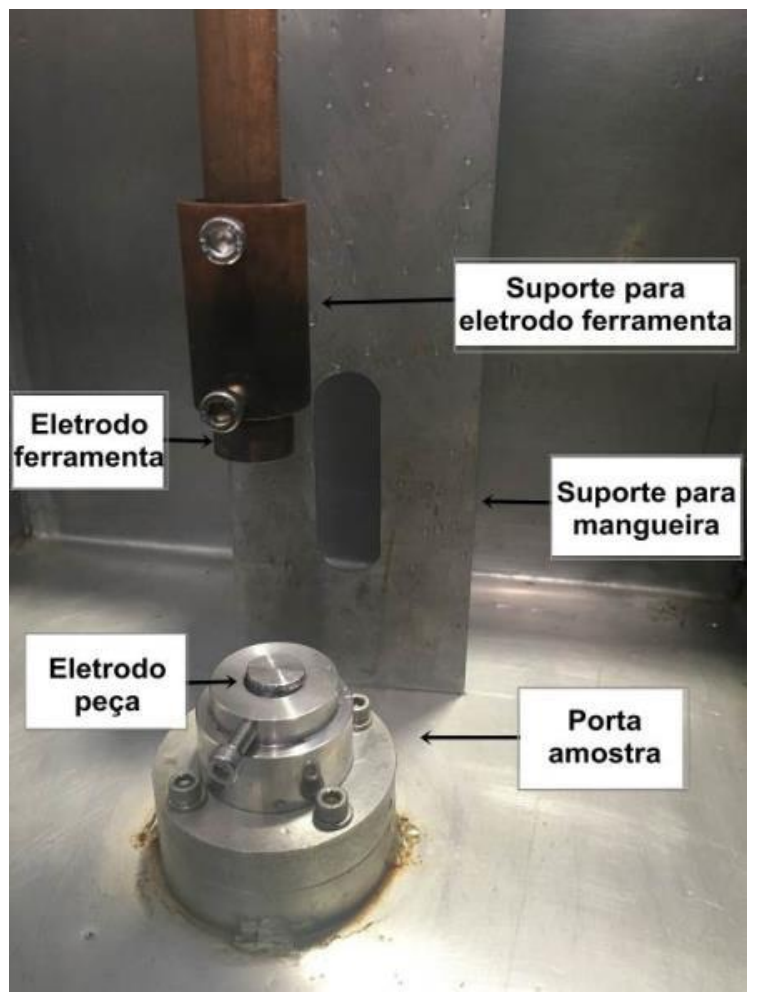

Figura 2: Adaptações máquina EDM para o ensaio.

Para realização dos testes, diversos parâmetros foram selecionados no painel de controle da máquina. Esses parâmetros estão listados na tabela 1.

Tabela 1: Parâmetros operacionais selecionados na máquina EDM para aplicação do processo NDE

\begin{tabular}{l|l}
\hline \multicolumn{1}{c|}{ PARÂMETRO } & ESPECIFICAÇÃo \\
\hline Polaridade do eletrodo ferramenta & Positiva \\
\hline Corrente & $40 \mathrm{~A}$ \\
\hline Tensão de trabalho & $50 \mathrm{~V}$ \\
\hline Tempo de pulso (Ton) & $100 \mu \mathrm{s}$ \\
\hline Tempo de pausa (Toff) & $1,5^{*}$ \\
\hline Fenda de trabalho (Gap) & $1,0^{*}$ \\
\hline Afastamento periódico da ferramenta & $3,0^{*}$ \\
\hline Velocidade do servo & $5,0^{*}$ \\
\hline Tempo de erosão & $5,0^{*}$ \\
\hline
\end{tabular}

*Parâmetros ajustados nos botões do painel do controle da máquina

\subsection{Metalografia}

Duas amostras, previamente seccionadas transversalmente ao sentido de usinagem, usinadas por duas condições diferentes, com e sem adição de pó abrasivo ao fluído dielétrico, foram preparadas por técnicas metalográficas após o término da usinagem por EDM.

No embutimento, utilizou-se uma resina epóxi termo endurecedora carregada com minerais, que possui baixa contração e boa aderência para minimizar abaulamento das amostras e preservar as bordas, para evitar, 
assim, que a camada refundida desprenda-se durante a preparação metalográfica da amostra. Após o embutimento, as amostras foram lixadas manualmente com auxílio de lixas de carbeto de silício com as seguintes granulometrias: 180, 220, 360, 400, 500, 600, 1200, 1500 e 2000, 2200 mesh. Um polimento posterior foi aplicado às amostras, utilizando politrizes manuais com pasta de diamante de 3 e $1 \mu \mathrm{m}$ até que a superfície apresentasse aspecto espelhado.

Após o espelhamento da superfície, o ataque químico foi realizado com uma solução denominada Kroll, composta de ácido fluorídrico $(\mathrm{HF})$, ácido nítrico $\left(\mathrm{NHO}_{3}\right)$ e água destilada, recomendado para ligas de titânio em concentrações $7 \mathrm{ml}, 5 \mathrm{ml}$ e $90 \mathrm{ml}$, respectivamente. As micrografias foram realizadas em microscópio óptico Fortel, que possui sistema integrado de captura de imagens Kontrol modelo M713, e permitiu a medição da camada nitretada, por meio da função de medição linear do software, o qual oferece uma interface gráfica bem adaptável e de fácil manuseio.

As espessuras das camadas nitretadas das duas amostras foram medidas em vinte pontos diferentes sob toda extensão do corpo de prova. Não foi possível realizar medição da camada refundida da amostra usinada com pó abrasivo, pois a mesma apresentou-se de forma fragmentada e irregular.

\subsection{Dureza}

Ao se observar os critérios, estabelecidos pela norma E384 - 17 da ASTM, a dureza da camada nitretada e do substrato foi mensurada pelo ensaio de microdureza Vickers (HV), com auxílio de um microdurômetro Shimadzu modelo HMV-2T E com capacidade de carga de 10 a 100 gf. Para o ensaio, utilizou-se carga de 10 gf por 15 segundos. As indentações foram realizadas na seção transversal de duas amostras previamente preparadas para o ensaio metalográfico, uma delas usinada com adição do pó abrasivo; e a outra sem adição do pó. Essas indentações foram executadas nas amostras em conjunto de três e espaçadas igualmente em torno de $25 \mu \mathrm{m}$, concentradas na camada nitretada e na matriz do material, com o objetivo de acompanhar o decréscimo da dureza ao se afastar da borda do material e próximas ao centro dessas regiões, para evitar interferências da borda no resultado da dureza.

Incorporado ao durômetro, há um microscópio óptico software Easy Test HMV-AD que com auxílio de uma câmara digital, integrada ao equipamento, captura imagens do perfil de dureza.

\subsection{Difração de raio-X}

As difrações foram obtidas por difração de raio-X convencionais, utilizando o difratômetro modelo Shimadzu XRD - 7000 X-Ray. Os ensaios foram realizados na superfície da amostra, na direção de usinagem. O principal objetivo dessa caracterização foi identificar os nitretos formados na superfície do titânio após NDE.

Duas amostras foram caracterizadas após usinagem: uma com adição do pó abrasivo; e outra sem a adição do pó. Também foram caracterizadas amostras do material base. Os parâmetros empregados no ensaio estão listados na tabela 2.

Tabela 2: Parâmetros adotados no ensaio de DRX

\begin{tabular}{|c|c|}
\hline PARÂMETRO & ESPECIFICAÇÃO \\
\hline Radiação & $\mathrm{CuK} \alpha$ \\
\hline Tensão & $40 \mathrm{kV}$ \\
\hline Corrente & $30 \mathrm{~mA}$ \\
\hline Tipo de varredura & $\theta-2 \theta$ \\
\hline Ângulo inicial de varredura $(2 \theta)$ & $20^{\circ}$ \\
\hline Ângulo final de varredura $(2 \theta)$ & $120^{\circ}$ \\
\hline Modo de varredura & Tempo fixo \\
\hline Passo de amostragem & $0,04^{\circ}$ \\
\hline Tempo de varredura por ponto & $1 \mathrm{~s}$ \\
\hline
\end{tabular}

\subsection{Rugosidade}

Um aparelho rugosímetro, modelo Rugosurf 20 da fabricante Tesa, mediu as rugosidades das superfícies erodidas com os diferentes fluidos dielétricos.

Os parâmetros selecionados estão de acordo com a norma NBR ISO 4287: 2002 e manual do usuário 
fornecido pelo fabricante. Por se tratar de valores significativamente altos de rugosidade, foi utilizado "cut-off" (comprimento de amostragem) de 2,5 mm e leitura nos parâmetros Ra, $\mathrm{Rz}, \mathrm{Rq}$ e Rt, respectivamente denominadas rugosidade média aritmética, rugosidade média, desvio médio quadrático e rugosidade total. Para adquirir maior confiabilidade, cada amostra foi avaliada por cinco medições.

\subsection{Microscopia eletrônica de varredura - MEV}

A etapa de caracterização por microscopia eletrônica de varredura (MEV) ocorreu em quatro amostras, duas usinadas com adição do pó abrasivo de $\mathrm{SiC}$, e duas, após processo, utilizando-se apenas água deionizada e uréia como fluído dielétrico.

\section{RESULTADOS}

\subsection{Formação da camada nitretada}

O resultado da análise microestrutural da seção transversal das amostras é apresentado nas figuras 3 e 4 . Observa-se, em ambos os casos, a formação de três regiões: mais superficial à face, denominada zona refundida (ZR), uma camada central, que é a camada nitretada e mais ao fundo, o metal base.

No processo de NDE, quando se utilizou como fluido dielétrico água deionizada e uréia, obteve-se camadas características desse processo; conforme pode ser observado na figura 3. Após vinte medições em pontos distintos da camada, realizou-se a análise estatística, que apresentou a média e desvio padrão da amostra. A espessura média da camada nitretada obtida é de $60 \mu \mathrm{m}$ e desvio padrão de $\pm 7,3$, que é menor que a espessura média obtida no processo; quando se adicionou pó abrasivo ao fluido dielétrico, conforme apresentado na figura 4.

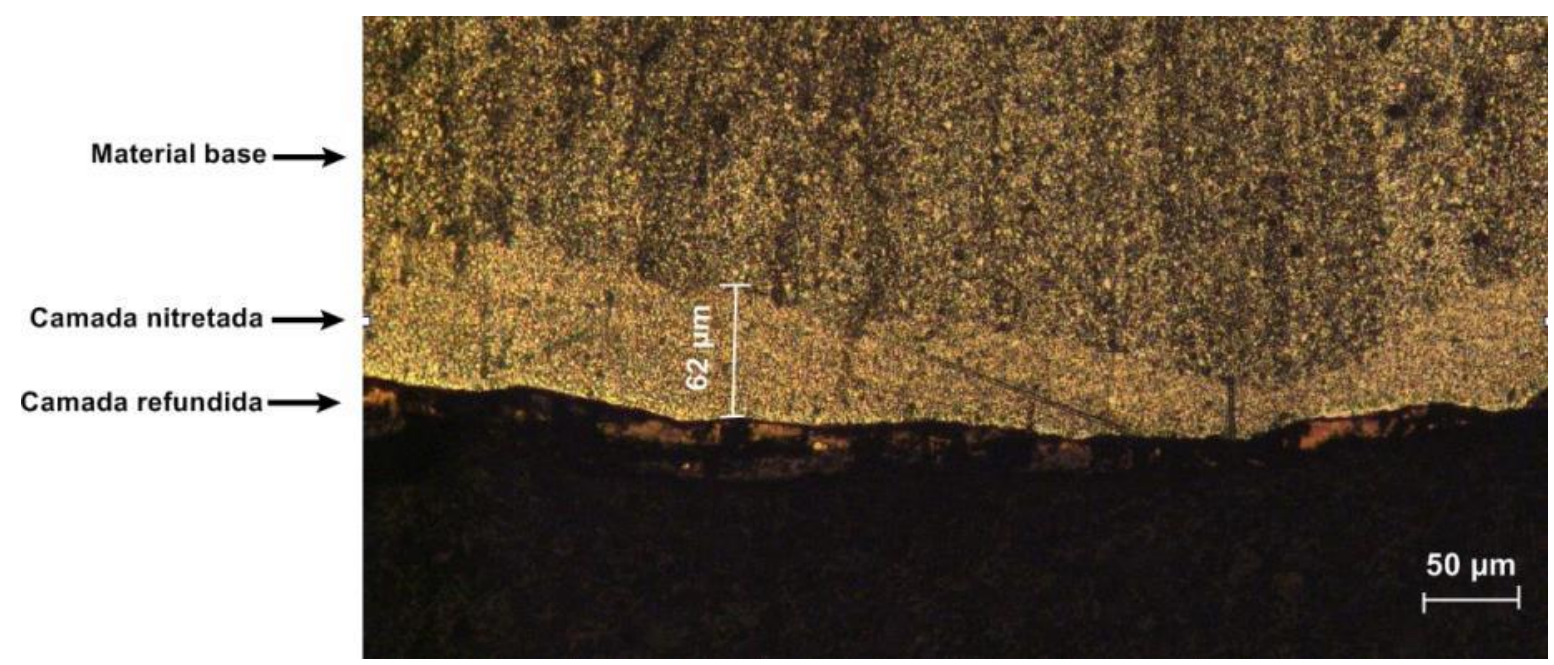

Figura 3: Microscopia óptica - ampliação de 100x da amostra de Ti-6Al-4V nitretada sem pó adicionado ao fluido dielétrico.

A figura 4 ilustra uma microscopia da seção transversal de uma amostra nitretada por EDM quando o pó de carbeto de silício de 600 mesh foi adicionado ao fluido dielétrico. Obteve-se espessura média da camada nitretada e desvio padrão em torno de $104 \mu \mathrm{m} \pm 16,40$, respectivamente, os valores obtidos são baseados em vinte medições da camada ao longo da seção transversal do corpo de prova. A camada refundida não é observada em toda extensão da amostra, e por essa razão, não foi possível estimar sua espessura. 


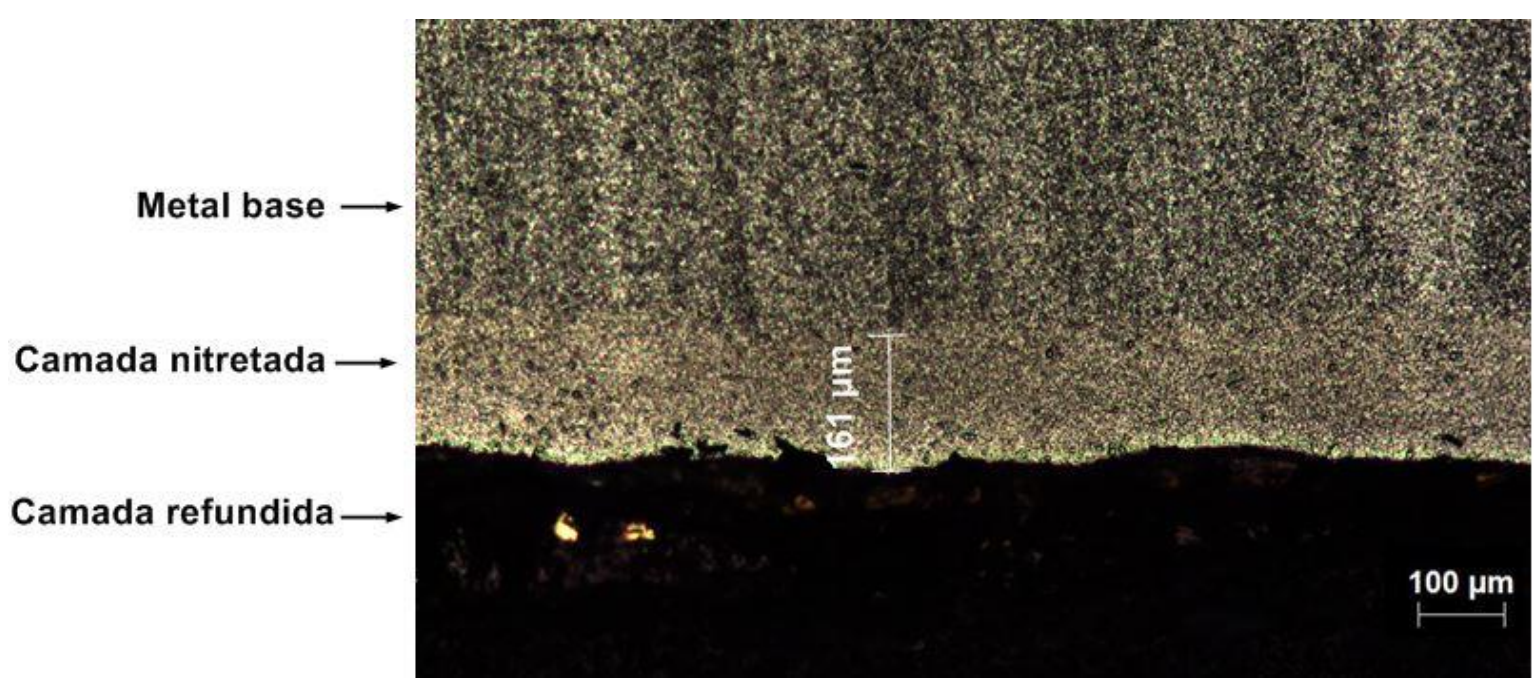

Figura 4: Microscopia óptica - ampliação de 100x da amostra de Ti-6Al-4V nitretada com pó de carbeto de silício adicionado ao fluido dielétrico.

\subsection{Dureza}

As seções transversais das amostras, usinadas por fluidos dielétricos distintos, foram submetidas ao ensaio de dureza. As indentações foram realizadas desde a superfície do material até a matriz, com intuito de verificar a profundidade da camada em função do tratamento. Foram feitas três indentações para cada posição de medição, espaçadas igualmente em $25 \mu \mathrm{m}$, iniciando-as próximo ao centro das regiões e a $25 \mu \mathrm{m}$ da borda de usinagem. Por essa razão, não houve medição em camada refundida, visto que, onde ocorreu a formação desta, sua espessura foi inferior aos $25 \mu \mathrm{m}$ estabelecidos. Utilizou-se carga de $10 \mathrm{gf}(98,07 \mathrm{mN})$ e tempo de carregamento de 15 segundos. Antes das medidas, as superfícies das amostras foram preparadas e polidas com pasta de diamante de 3 e $1 \mu \mathrm{m}$.

A tabela 3 apresenta os resultados médios e desvio padrão da microdureza Vickers obtidos quando utilizou-se como fluido dielétrico água deionizada e uréia com e sem adição de $\mathrm{SiC}$ em pó, comparando com o material base da liga Ti-6Al-4V.

Tabela 3: Valores de microdureza Vickers após usinagem sem e com adição de pó SiC

\begin{tabular}{c|c|c|c}
\hline \multirow{2}{*}{} & \multirow{2}{*}{$\begin{array}{c}\text { MATERIAL BASE } \\
\text { (TI-6AI-4V) }\end{array}$} & USINAGEM SEM Pó & USINAGEM COM Pó SIC \\
\cline { 3 - 4 } & $294,1 \pm 5,8$ & $399,3 \pm 31,9$ & $446,5 \pm 22,1$ \\
\hline Dureza HV & - & $35,8 \%$ & $51,8 \%$ \\
\hline Aumento da dureza & - &
\end{tabular}

Em ambos os casos (usinagem sem ou com pó abrasivo SiC), observa-se o aumento relativo da dureza na camada nitretada do material. Os resultados mostram um acréscimo médio de $36 \%$ da dureza do material quando a usinagem foi realizada sem adição de pó abrasivo e $52 \%$ quando se acrescentou o pó ao fluído dielétrico.

A figura 5 apresenta o perfil de dureza para amostras usinadas, a partir de NDE, sem e com adição do $\mathrm{SiC}$ em pó ao fluído dielétrico. É possível observar um decréscimo de dureza à medida que as indentações se afastam da borda do material. Um ganho de dureza considerável é observado até próximo de $100 \mu \mathrm{m}$, para usinagem sem pó, e $125 \mu \mathrm{m}$, na usinagem com pó. A partir de então, há um decréscimo progressivo, e o valor de dureza se aproxima do valor do material base. 


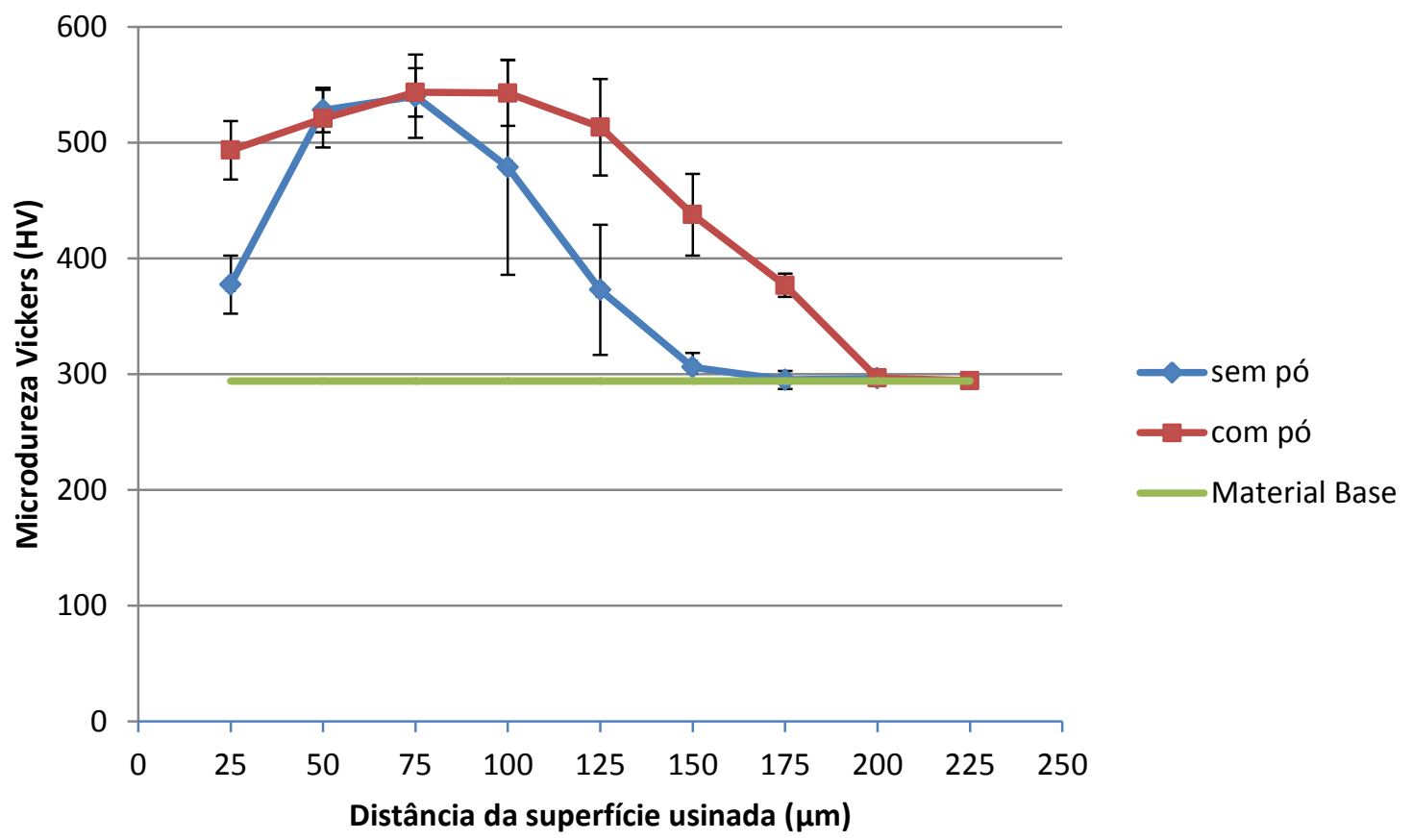

Figura 5: Perfil de dureza da seção transversal das amostras usinadas sem e com adição de pó abrasivo SiC.

\subsection{Difração de raio-X}

Por meio da análise difratográfica, foi possível identificar a presença do titânio como fases majoritárias e alguns picos identificados como nitretos de titânio. A figura 6 apresenta a sobreposição da análise da amostra da liga de titânio Ti-6Al-4V antes e após usinagem NDE sem adição do pó de carbeto de silício no fluido dielétrico. Os picos identificados nas posições $37^{\circ}, 43^{\circ}, 63^{\circ}$ são de nitretos de titânio e compatíveis com os picos identificados por YAN et al. [2].

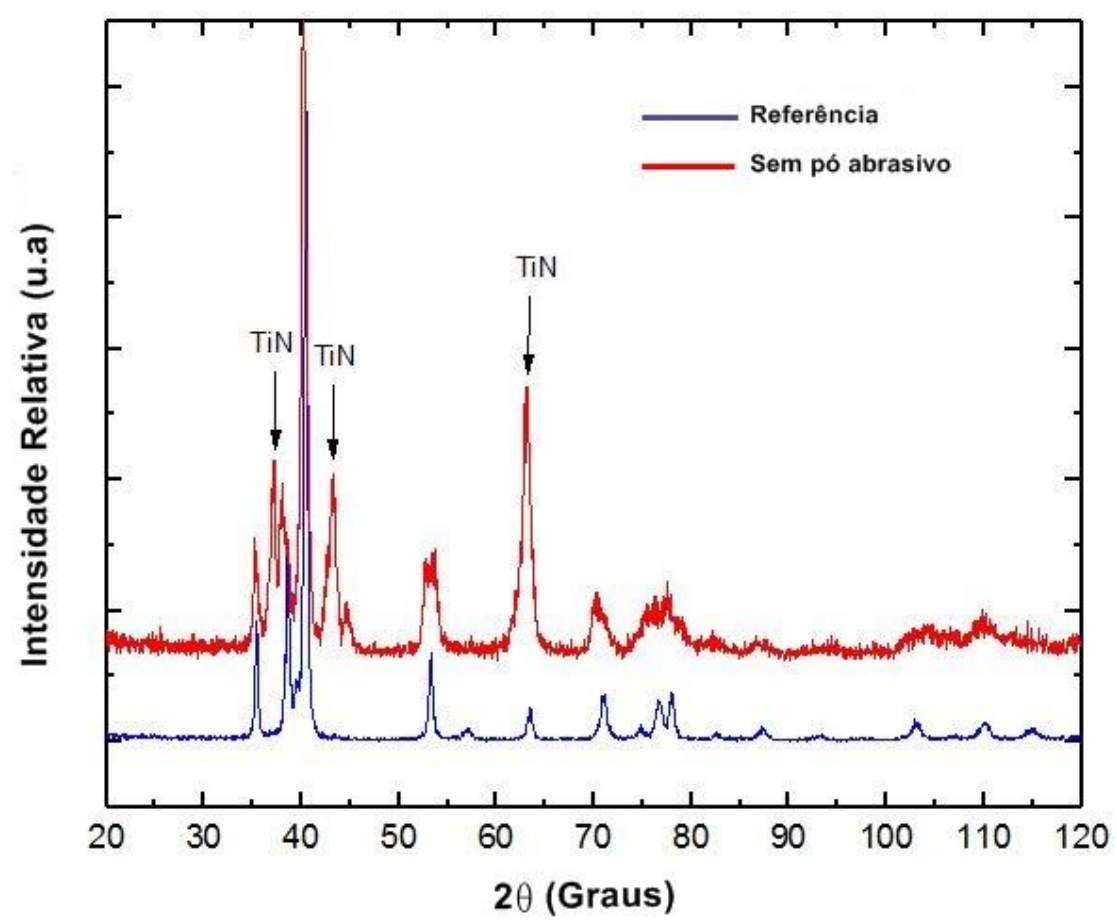

Figura 6: Difratograma da amostra usinada utilizando-se apenas água deionizada e uréia como fluído dielétrico. 
O difratograma da figura 7 refere-se a uma amostra nitretada na qual se utilizou como fluido dielétrico água deionizada, uréia e adição de pó abrasivo.

Os picos identificados nas posições $37^{\circ}, 43^{\circ}, 63^{\circ}, 75^{\circ}$ e $79^{\circ}$ são de nitretos de titânio e compatíveis com os picos identificados por YAN et al. [2].

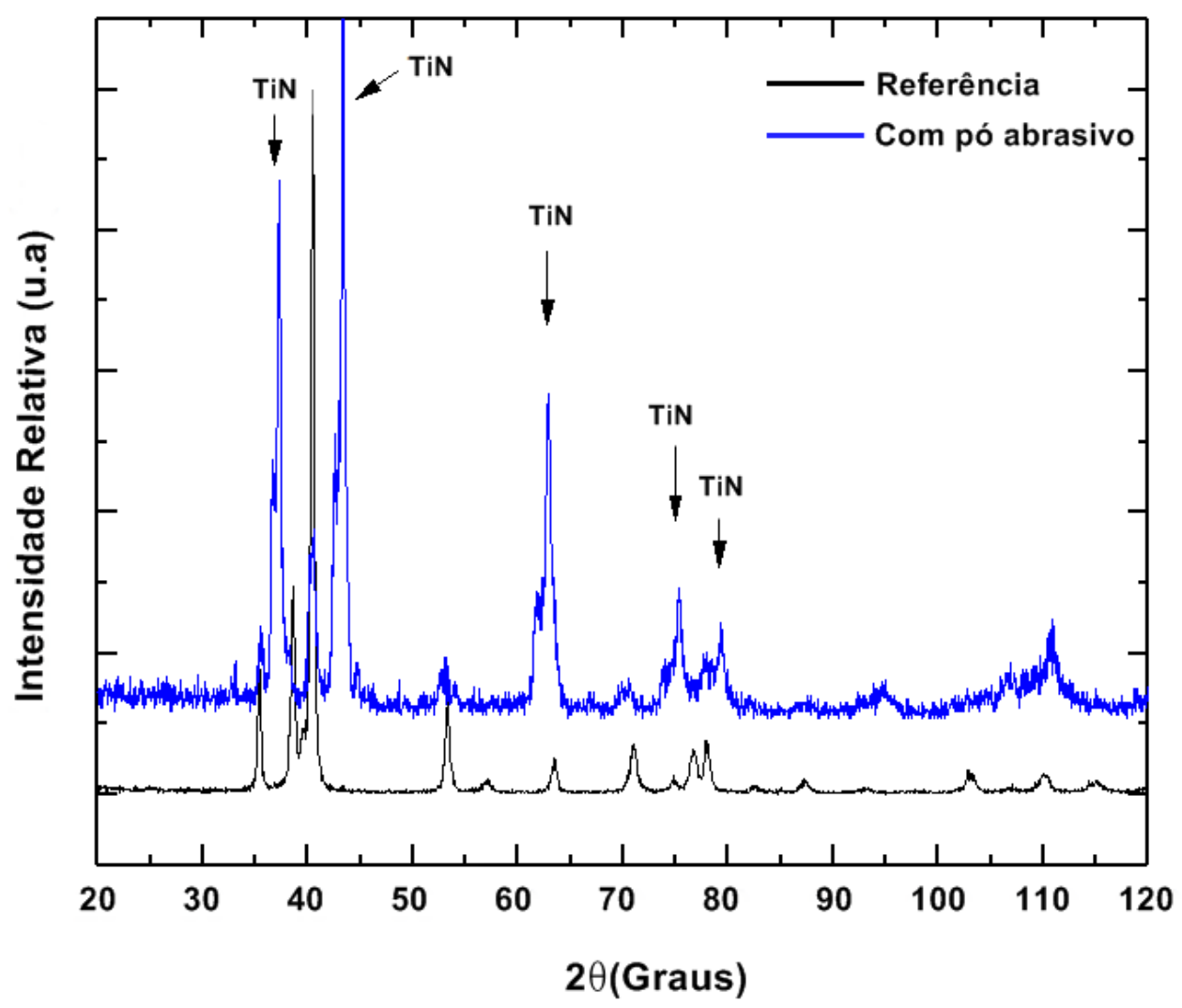

Figura 7: Difratograma da amostra usinada com o pó abrasivo SiC incorporado ao fluído dielétrico.

\subsection{Rugosidade}

As medidas de rugosidade foram obtidas por meio de rugosímetro portátil, considerando duas direções diferentes da amostra, e os valores representam a média e o desvio padrão de cinco medições de amostras usinadas com e sem pó abrasivo SiC. Na figura 8, comparam-se os valores obtidos em diferentes parâmetros de rugosidade. 


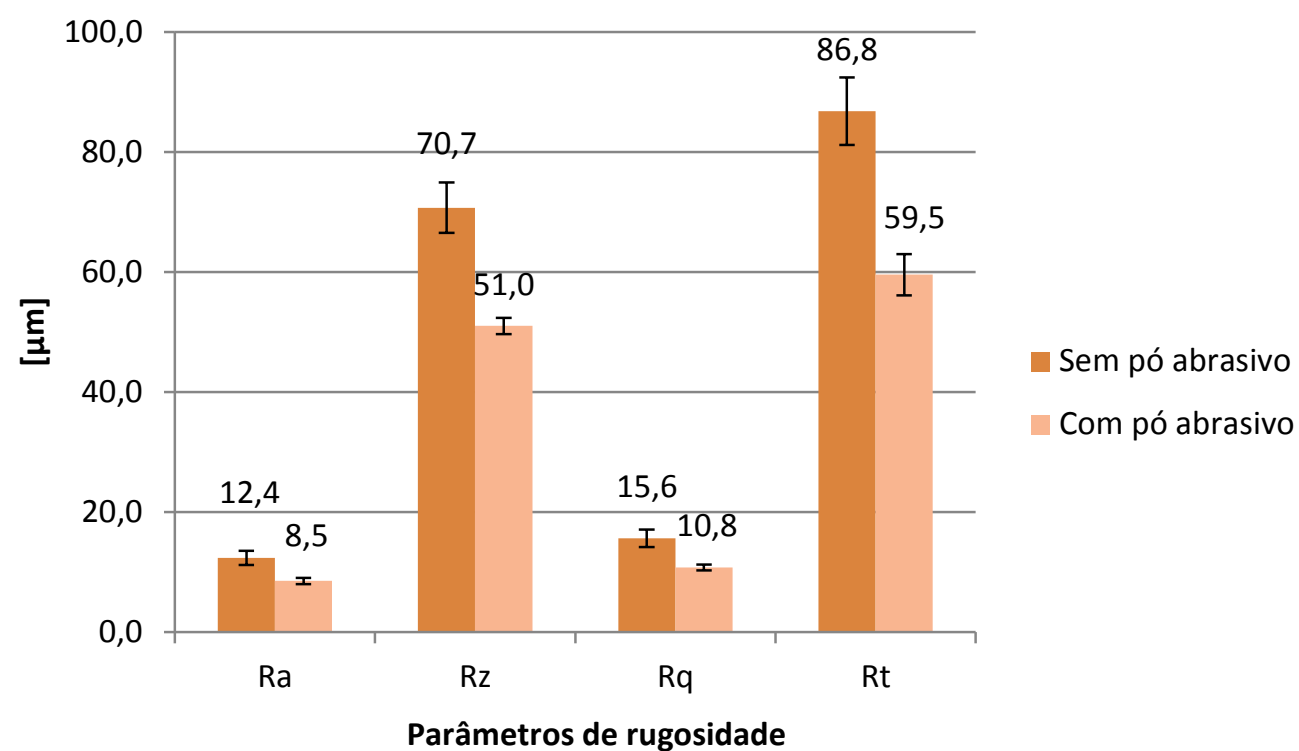

Figura 8: Gráfico da média das rugosidades das amostras usinadas com e sem adição de pó abrasivo ao fluído dielétrico.

Observa-se, na tabela 4, que houve redução da rugosidade superficial em torno de $31 \%$ quando se adicionou ao fluido dielétrico o pó abrasivo de SiC. Esse resultado vai ao encontro da pesquisa de CHOW et al. [12] , que afirma redução da rugosidade em processo de EDM quando se adiciona o pó de carbeto de silício ao fluído dielétrico.

Tabela 4: Avaliação da rugosidade superficial de amostras usinadas com e sem pó adicionado ao fluido dielétrico.

\begin{tabular}{l|c|c|c|c}
\hline \multirow{2}{*}{ FLUído DIELÉTRICO } & \multicolumn{4}{|c}{ PARÂMETRO DE RUGOSIDADE $(\boldsymbol{\mu m})$} \\
\cline { 2 - 5 } & $\mathbf{R a}$ & $\mathbf{R z}$ & $\mathbf{R q}$ & $\mathbf{R t}$ \\
\hline Sem pó abrasivo & $12,4 \pm 1,2$ & $70,7 \pm 4,2$ & $15,6 \pm 1,5$ & $86,8 \pm 5,6$ \\
\hline Com pó abrasivo & $8,5 \pm 0,5$ & $51 \pm 1,3$ & $10,8 \pm 0,5$ & $59,5 \pm 3,4$ \\
\hline Redução percentual da rugosidade & $31 \%$ & $28 \%$ & $31 \%$ & $31 \%$ \\
\hline
\end{tabular}

\subsection{Microscopia Eletrônica de Varredura}

A figura 9 apresenta imagens de MEV das amostras usinadas por NDE com e sem adição do pó abrasivo de SiC. A morfologia da superfície é característica da usinagem por EDM, na qual é possível se observar crateras, poros e partículas refundidas, que são ocasionadas pela alta temperatura oriundas do processo. É possível notar uma redução da profundidade das crateras da superfície na usinagem com a adição do pó. 

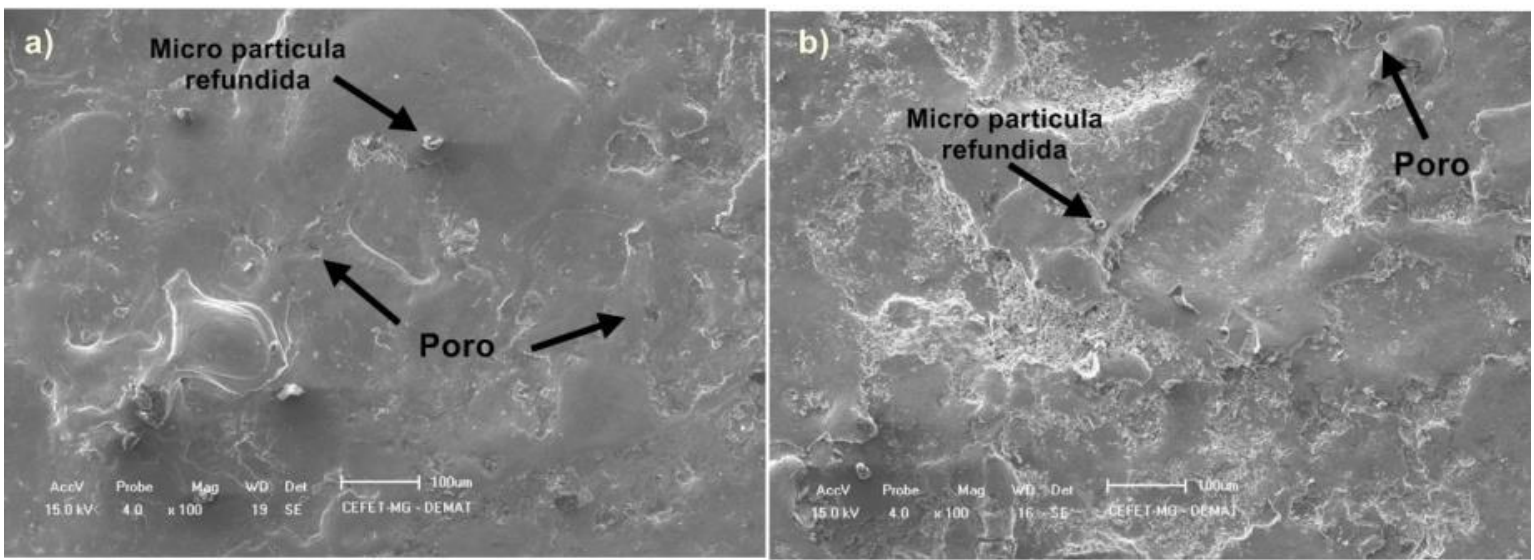

Figura 9: Microscopia eletrônica de varredura da superfície a) usinada com adição de pó abrasivo SiC e b) usinada sem adição de pó abrasivo $\mathrm{SiC}$.

\section{DISCUSSÃO}

Nas análises metalográficas, apresentadas nas figuras 3 e 4, é possível observar a formação de regiões distintas. $\mathrm{Na}$ fronteira entre o material e superfície, há a formação da região denominada zona refundida (ZR), formada em decorrência da resolidificação do material na superfície da amostra pelas temperaturas altas geradas pelas descargas elétricas [13]. Nesse experimento, não foi possível verificar uma formação da camada refundida em toda a extensão da amostra, o que pode estar associado à alta porosidade dessa camada e sua deterioração no processo de preparação metalográfica, apesar dos cuidados tomados.

A camada central é a região que sofreu o efeito do processo térmico, denominada camada nitretada. Essa camada possui coloração mais clara, e a existência dela pode ser atribuída à incorporação de nitrogênio liberado pela uréia, já que, em experimentos, realizados sem a adição da uréia; observa-se apenas a camada refundida e o metal base [13].

Observa-se formação de camadas mais espessas quando se adicionou o pó abrasivo de carbeto de silício ao fluído dielétrico, que pode se associar à alteração da intensidade e à concentração da descarga [14]. O fato de o pó misturar-se ao fluído, além de permitir maior dispersão da descarga, reduz a capacitância no gap pelo aumento do seu comprimento em pelo menos cinco vezes em relação ao EDM convencional [15], reduzindo a possibilidade de descargas anormais; devido ao gap maior, gerar mais estabilidade na usinagem.

Outra importante observação, é que, além de obter camadas mais profundas, quando a usinagem foi realizada com o pó, a dureza obtida também foi maior. Além da incorporação do nitrogênio, oriundo da uréia, formando nitretos de titânio na superfície do material, acredita-se haver incorporação de partículas do carbeto de silício na superfície do material, formando compostos intermetálicos e precipitados de carbonetos [16].

Analisando a figura 5, observa-se que, inicialmente, a dureza na superfície é menor; após se afastar da superfície do material, a dureza aumenta progressivamente e decai quando não se tem mais camada composta por nitretos (material base), o que corrobora com a pesquisa de HASÇALIK e ÇAYDAS [17], que investigaram a superfície da liga de titânio após EDM. Eles identificaram que, abaixo da camada refundida, há uma camada de menor dureza devido à baixa condutividade térmica da liga Ti-6Al-4V.

As análises de DRX revelam que, em ambas as condições de NDE, há formação de nitretos de titânio e, de acordo com YAN et al. [2], o nitreto de titânio é formado pela reação química entre o metal base e o nitrogênio decomposto da solução aquosa contendo ureia. Pesquisas realizadas por SAHU et al. [16] indicam que a pirólise do fluído dielétrico também contribui para o enriquecimento na superfície usinada e que, além disso, as partículas de pó adicionadas ao fluído dielétrico podem contribuir para a migração do material para a superfície usinada, o que podem ser os picos não característicos e não identificados na análise de DRX apresentadas.

KURIACHEN e MATHEW [18] confirmam, em suas pesquisas, a transferência de partículas do eletrodo ferramenta e do fluído dielétrico para a superfície da peça, devido à dissolução do eletrodo e à decomposição do dielétrico e o pó de $\mathrm{SiC}$, usado em sua pesquisa, também é fundido ao eletrodo peça e ferramenta ao absorver a energia do canal de plasma.

A análise da rugosidade superficial evidencia significativa redução em torno de $31 \%$. Segundo CHOW et al. [12], esse fenômeno se deve a baixa resistência elétrica das partículas em pó que torna a solução dielétrica mais condutora e a distância do gap mais ampla, dispersando a energia de descarga, que irá reduzir a rugosidade. 
Quando a tensão necessária é estabelecida entre a peça de trabalho e o eletrodo ferramenta, as partículas de pó, presentes no dielétrico, energizam-se e atuam como meio condutor entre a peça de trabalho e a ferramenta, promovendo uma maior fenda de trabalho. Devido à formação de cadeias de partículas condutoras, ocorre a ponte entre os eletrodos e reduz o efeito isolante do dielétrico. Assim, existem chances de curtos-circuitos aumentarem-se e há maior dispersão da descarga [18].

$\mathrm{O}$ aspecto superficial pode ser observado nas análises do MEV, nas quais é possível observar uma redução das crateras e aspereza na superfície usinada. CHOW et al. [12] evidenciaram, em seu experimento, que como o pó de SiC possui uma alta dureza, seu fluxo e movimento na fenda de trabalho podem contribuir para o polimento da peça durante os processos de EDM, reduzindo assim a rugosidade superficial.

Pode-se afirmar que a nitretação por descargas elétricas com adição de pó abrasivo de carbeto de silício é uma opção viável no processo, quando se objetiva, além do aumento da dureza superficial, oriunda do processo de NDE, como também a redução da rugosidade superficial.

\section{CONCLUSÕES}

Ensaios foram conduzidos com o objetivo de avaliar a formação da camada nitretada por NDE, quando se utilizou eletrodo de grafita e como fluido dielétrico água deionizada e uréia com adição de pó abrasivo de carbeto de silício (SiC). Na análise, foi observada a formação de camadas com espessuras significativas, em torno $104 \mu \mathrm{m}$, quando se adicionou o pó e média de $60 \mu \mathrm{m}$ sem adição de pó abrasivo.

O nitrogênio diluído no fluído dielétrico implantou-se na superfície da amostra formando os nitretos de titânio. $\mathrm{O}$ ensaio de difração de raio-X evidenciou a formação desses nitretos e foi a base para essa comprovação.

A partir do ensaio de microdureza Vickers, foi possível identificar um acréscimo médio de 52\%, quando a usinagem foi realizada, acrescentando o pó ao fluído dielétrico.

Com relação ao acabamento superficial, houve redução de rugosidade utilizando-se o pó misturado ao fluído dielétrico. Essa redução pode chegar a $31 \%$ em relação à amostra nitretada sem pó abrasivo.

Após investigação, conclui-se que os resultados obtidos são satisfatórios e indicam viabilidade no processo de nitretação por descargas elétricas da liga de titânio Ti-6Al-4V ao acrescentar pó abrasivo de carbeto de silício ao fluído dielétrico. Foram apresentados ganhos significativos de dureza superficial, uma necessidade para a maioria das aplicações da liga Ti-6Al-4V e redução da rugosidade superficial, uma constante busca em processos de EDM. Com a exigência contínua do mercado industrial em integração e redução de custos dos processos industriais, a NDE, com adição do pó abrasivo, pode ser uma solução desejável para a integração de processos. Visto que não houve nenhuma mudança significativa na característica da máquina de EDM, com o aprimoramento de pesquisas relacionadas ao assunto, pode-se, no futuro, viabilizar o uso industrial dessa tecnologia.

\section{AGRADECIMENTOS}

Os autores agradecem ao Departamento de Engenharia de Materiais do CEFET-MG pela cessão de sua estrutura para realização dos experimentos e à PUC-MINAS por ceder seus laboratórios para realização de ensaios.

\section{BIBLIOGRAFIA}

[1] EL-HOFY, H. A.G Advanced Machining Processes - Nontraditional and Hybrid Machining Processes. 1ed. Egypt, McGraw Hill Professional, 2005.

[2] YAN, B. H., TSAI, H. C., HUANG, F. Y. "The effect in EDM of a dielectric of a urea solution in water on modifying the surface of titanium”, International Journal of Machine Tools \& Manufacture, v. 45, pp. 194-200. Sep. 2004.

[3] CAMARGO, B. C., COSTA, H. L., RASLAN, A. A. "Endurecimento superficial de uma liga Ti-6al-4V por meio de usinagem por descargas elétricas”, In: COBEF - V Congresso Brasileiro de Engenharia de Fabricação, Abr. Belo Horizonte, 2009.

[4] SANTOS, R. F., "Nitretação por EDM no aço AISI 4140”, Tese de D. Sc., Uberlândia, MG, Brasil, 2013.

[5] SILVA, S. P. “Avaliação da resistência à fadiga axial do aço ABNT 4140 nitretado por descargas elétricas”, Tese de M. Sc, DEMAT/CEFET, Belo Horizonte, MG, Brasil, 2016.

[6] RAZAN, M. A., ABDUL-RANI, A. M., NANIMINA, A. M., "Improving EDM efficiency with silicon car- 
bide powder-mixed dielectric fluid", International Journal of Materials, Mechanics and Manufacturing, v. 3, n. 2, pp.40-43. Feb. 2015.

[7] JESWANI, M. L., "Effect of the addition of graphite powder to kerosene used as the dielectric fluid in electrical discharge machining", Wear - International Journal on the Science and Technology of Friction, Lubrication and Wear, v. 70, pp. 133 - 139. May. 1981.

[8] ASSARZADEH, S., GHOREISHI, M., “A dual response surface-desirability approach to process modeling and optimization of $\mathrm{Al} 2 \mathrm{O} 3$ powder-mixed electrical discharge machining (PMEDM) parameters", The International Journal of Advanced Manufacturing Technology, v. 64, pp. 1459-1477, Feb. 2013.

[9] NANIMINA, A. M., RANI, A. M. A., GINTA, T. L., “Assessment of powder mixed EDM: A review”. MATEC Web of Conferences, v. 13, pp. 1-5. Jul. 2014.

[10] MARASHI H., JAFARLOU D. M., SARHAN A. A. D., et al. "State of the art in powder mixed dielectric for EDM applications”, Precision Engineering. v. 46, pp.11-33. Oct. 2016.

[11] RIZI, M. S., RAZAVI, G. R., OSTADMOHAMADI, M., et al. “Optimization Electro Discharge Machining of Ti-6Al-4V Alloy With Silicon Carbide Powder Mixed”, Advanced Materials Research, v. 566, pp. 466469. Sep. 2012.

[12] CHOW, H. M., YANG, L. D., LIN, C. T., et al. "The use of SiC powder in water as dielectric for microslit EDM machining”, Journal of Materials Processing Technology, v. 195, pp. 160-170. Jan. 2008.

[13] CAMARGO, B. C., ARANTES, J. A., RASLAN, A. A., "Estudo a viabilidade da nitretação de liga de titânio através do processo de usinagem por descargas elétricas”, In: $16^{\circ}$ POSMEC Simpósio de Pós-Graduação em Engenharia Mecânica, Uberlândia, 2006.

[14] KLOCKE, F., ANTONOGLOU, G., THOMAIDIS, D., "The effects of powder suspended dielectrics on the thermal influenced zone by electrodischarge machining whit small discharge energies", Journal of Materials Processsing Technology. v. 149, pp. 191-194. Jun. 2004.

[15] TAKAWASHI, T., KOBAYASHI, K., "EDM by powder suspended working fluid”, In: Proceedings of the International Symposium for Electro-Machining, Japan, 1989.

[16] SAHU, S. K., JADAM, T., DATTA, S., et al., "Effect of using SiC powder-added dielectric media during electrodischarge machining of Inconel 718 superalloys", Journal of the Brazilian Society of Mechanical Sciences and Engineering, v. 40, n. 330, pp. 1- 19, Jun. 2018.

[17] HASÇALIK A., ÇAYDAS U., "Electrical discharge machining of titanium alloy (Ti-6Al-4V)", Science Direct., v. 253, pp. 9007-9016. Sep. 2007.

[18] KURIACHEN, B., MATHEW, J., "Experimental Investigations into the Effects of MicroelectricDischarge Milling Process Parameters on Processing Ti-6Al-4V", Journal Materials and Manufacturing Processes, v. 30, n. 8, pp. 983-990, May. 2014.

\section{ORCID}

Roberta Nunes Nery dos Santos Ernane Rodrigues da Silva Victor Souza Esteves Lima Aderci Freitas Filho https://orcid.org/0000-0002-1918-1089

https://orcid.org/0000-0001-6035-6736

https://orcid.org/0000-0002-1178-7916

https://orcid.org/0000-0003-1650-3094 